theorem - surely the only time that these two items have been neighbours in the same book - and this serves to indicate the book's quirkiness.

Simon Singh is the author of Big Bang (Fourth

Estate, 2004), a history of cosmology.

\section{Wine with a deep flavour}

The Winemaker's Dance: Exploring Terroir in the Napa Valley

by Jonathan Swinchatt \& David G. Howell University of California Press. 2004. 243 pp. $\$ 35.95, £ 22.95$

\section{George W. Moore}

The taste of a wine depends on more than just the variety of the grape from which it is made. Winemakers and wine connoisseurs are concerned with terroir (pronounced 'tair-wahr'), which refers to everything else that controls the flavour of wine: climate, subsoil and even the manipulations done in the winery.

Many winemakers believe that the taste of wine comes from the soil that supports the vines. But the soil is only about a metre thick, whereas the roots of the vines extend down about 10 metres or more. The soil is in equilibrium with the local climate: its clay and organic components smooth out the delivery of water to the plants, and cationexchange processes supply major nutrients. But the minor compounds that control the taste come from the much more voluminous subsoil. The bedrock slowly weathers under the action of water, carbon dioxide and organic acids. This process delivers a continuous flux of subsoil-dependent compounds to the vines, and is a key component of the local terroir. In The Winemaker's Dance, geologists Jonathan Swinchatt and David Howell evaluate every aspect of the terroir of a small but well known winemaking region and place their findings in a global context.

The Napa Valley, northeast of San Francisco, is in many ways similar to the famous Bordeaux region of France. They are at similar latitudes on the west coasts of continents, and principally grow the warmclimate grape variety Cabernet Sauvignon. They are both about 50 kilometres from their respective oceans, and large estuaries - San Francisco Bay at Napa and the Gironde at Bordeaux - provide the cool night-time temperatures that preserve the acidity of their premium wines.

The most expensive Napa Valley wines grow on alluvial fans (known locally as 'benches'), which are piles of gravel and interbedded silt that have streamed down off the flanking mountains. At Bordeaux, the counterparts to Napa's alluvial fans are

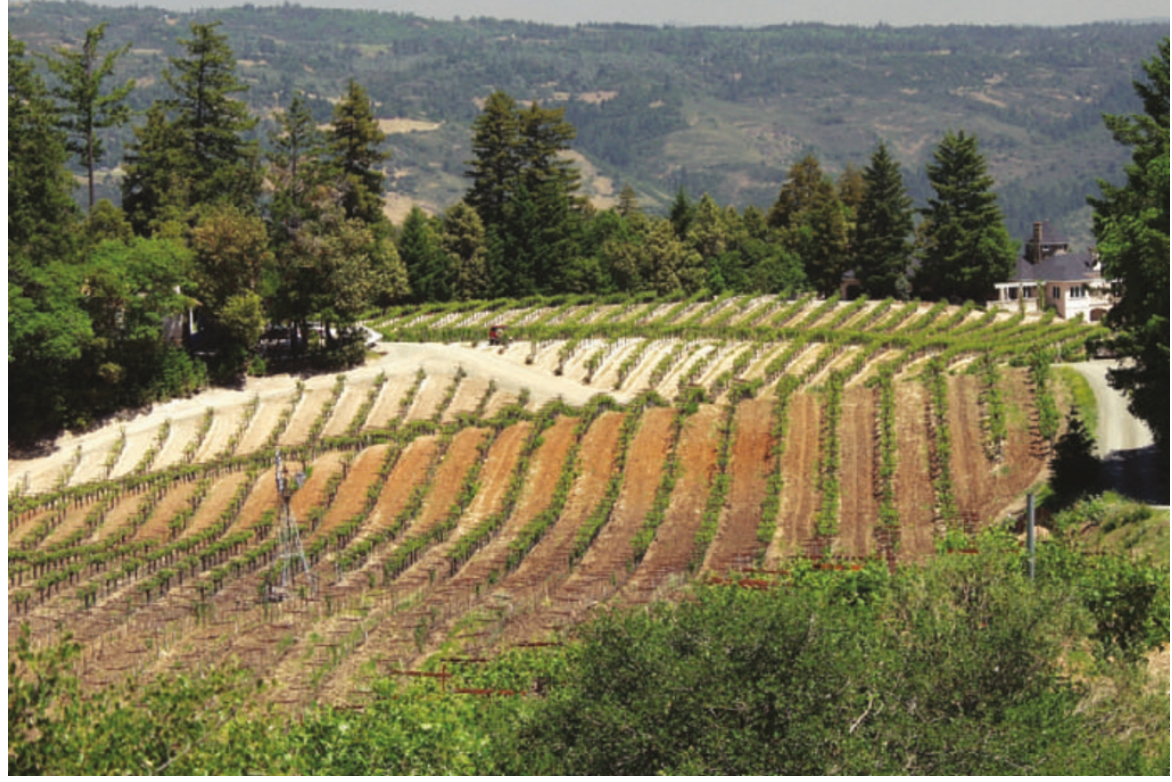

I'm getting something earthy: differences in bedrock can affect both soil colour and a wine's flavour.

the graves (gravel mounds, again interbedded with silt) formed by streams during ice-age low stands of the estuary.

In an effort to link the taste of wine to the subsoil geology, the authors studied Diamond Creek Vineyards, where the vines are planted on upland slopes at the north end of Napa Valley. The 8-hectare property is cut through by a network of faults that juxtaposes three dissimilar geologic blocks. During vineyard development, the owner recognized three strongly contrasting soil colours, and used them to divide the property into three vineyards. These were planted in 1968 with Cabernet Sauvignon cuttings from two first-growth vineyards at Bordeaux.

Throughout its history, Diamond Creek has had three vineyard-designated bottlings. Similar winemaking practices are used for each but the wines consistently taste different. Wine from Red Rock Terrace (which has a basaltic lava subsoil) has velvety tannins with rich cherry and blackcurrant flavours; that from Volcanic Hill (volcanic-ash-bearing sandstone) has tannins that are youthfully firm but long-lived with berry and smoky flavours; and wine from Gravelly Meadow (pebbly stream sediment) has firm tannins with herb, blackberry and earthy flavours.

Two major factors affect the subtleties of wine taste. The first is the 'character' of the wine - the grape variety plus all the elements of its terroir - and the second is the physiology of the people doing the tasting. Tastes vary: one person's crème de la crème is another person's plonk

To investigate the effect of local terroir on the palettes of ordinary consumers, Swinchatt and Howell conducted a blind tasting in 2002, serving eight premium Napa Valley wines with a meal. Most participants ranked the wines differently when they first tasted them to when they tried them again with a meal. When asked which of the eight they preferred overall, the votes were spread quite evenly. In an extreme case of differential preference, one person found the aroma of one wine to be particularly offensive, whereas another said of it: "I'd like to have a bowl of that beside my bed, just to smell."

This variation in personal preference is in marked contrast to the 'expert' opinion of wine-ranking services, which tend to favour blockbuster wines that are extremely intense, particularly on first tasting. This has led to winemakers letting their grapes hang as long as possible on the vines, and extending the time that the wines macerate on the grape skins. Swinchatt and Howell deplore the homogenization that this is causing to the taste of the world's wines. They recommend that consumers ignore the wine-ranking services, seek out diversity, and savour it. George W. Moore is in the Department of Geosciences, Oregon State University, Corvallis, Oregon 97331, USA.

\section{The quantum Universe}

\section{Science and Ultimate Reality: Quantum Theory, Cosmology and Complexity}

edited by John D. Barrow, Paul C. W. Davies \& Charles L. Harper, Jr

Cambridge University Press: 2004. 742 pp. $£ 40, \$ 60$

\section{Frank Close}

In the centenary year of Einstein's seminal contributions to human culture, Science and Ultimate Reality celebrates the 90th birthday of John Wheeler, who took two of Einstein's ideas and created new branches of science. The physics of the twentieth century was built on the twin pillars of Einstein's general theory of relativity and quantum mechanics. The former describes the macroscopic Universe of space-time and gravitation, and the latter is a theory of matter and radiation at subatomic dimensions. These two different 


\section{Museum \\ Waxing and waning}

The art of using wax models to demonstrate anatomy in three dimensions reached its zenith during the eighteenth century in the work of Ercole Lelli, in Bologna, and Clemente Susini, in Florence.

The most renowned collections of wax anatomical models are displayed in museums in these two Italian cities. But the Orfila Museum at the University of Paris V in France also holds important examples, including later works such as this 1847 model by one of the university's own anatomists, which was created for the museum's opening.

If you want to see the Paris collection, you may need to be quick, however. Unlike the Italian museums, the Orfila has struggled to survive, despite having been listed as a French National Heritage treasure in 1991. The university is reclaiming the exhibition rooms, and the museum's entire collection will be packed away into a basement later this year.

The Paris museum's collection has always been subject to dramatic swings in fortune. In the Second World War, for example, many of the wax models made by anatomist Jean-Baptiste Laumonier at the beginning of the nineteenth century were used to make candles, and only a few hundred remain in the collection today.

Despite this, the museum still hosts almost 6,000 historical items. These include, in addition to the wax models, anatomical models using other early twentieth-century techniques and materials. There are also casts of brains commissioned by neuropathologist Paul Broca - best remembered for his discovery of the part of the brain that controls speech - and an extensive collection of anthropological specimens, including Neanderthal and Australopithecus skulls and bones.

The museum can be visited by appointment. Achim Schneider www.biomedicale.univ-paris5.fr/anat

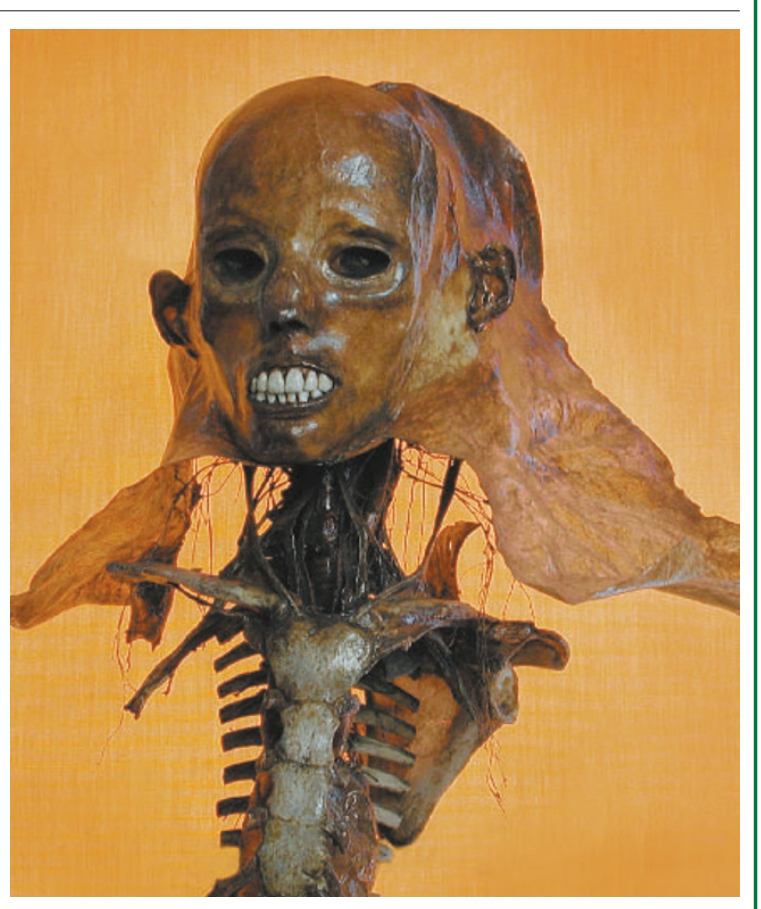

theories seem to be incompatible, but Wheeler insisted that, at some level, quantum effects must have a meaningful impact on gravitational physics. And because Einstein's theory intimately links gravitational physics with geometry, the net result must be some sort of quantum space-time dynamics. It was using this reasoning that Wheeler predicted in 1957 the existence of spacetime foam, one of many of his ideas that survive to this day.

Wheeler is popularly known for having

\section{IMAGE}

UNAVAILABLE FOR COPYRIGHT REASONS

A sign of success: John Wheeler is credited with coining the phrase 'black hole'. coined the phrase 'black hole', and professionally for his wide range of profound contributions in physics, ranging from the very large to the smallest scales of size. Gravitation was reborn, with Wheeler's influence, as a mainstream branch of science, leading to the explosive growth in astrophysics and cosmology that we see today. At the other extreme of scale, he developed the theory of nuclear rotation, with Edward Teller, and the fundamentals of electrodynamics, with Richard Feynman. And it was Wheeler's seminal question that led to the perception of the positron as an electron travelling backwards in time.

His 90th birthday was celebrated with a symposium attended by a metaphorical galaxy of scientific stars, and this book records the event. Do not be put off by its length: at over 700 pages this is still only about ten pages per year of active research, and this is one of those rare volumes where quantity is matched by quality.

With such a variety of contributions ranging from quantum reality (by Freeman Dyson and others), big questions in cosmology (including articles by Andreas Albrecht, John D. Barrow and Andrei Linde), higher dimensions (Lisa Randall) and the emergence of life (George Ellis) - how can a review do justice to them all? Perhaps I should focus on the man himself, aptly summarized in a readable and insightful opening chapter by Paul Davies.

Wheeler's gift has been in asking questions that are, in the modern parlance, 'outside the box'. While most of us rack our brains trying to determine and understand the implications of nature's laws, Wheeler wondered whether the very concept of physical laws might be an emergent property. Could law-like behaviour emerge stepwise from the ferment of the Big Bang, instead of being mysteriously and immutably imprinted on the Universe at the instant of its birth? As Davies says: "Wheeler was breaking a 400 year old scientific tradition of regarding Nature as subject to eternal laws."

As students we learn quantum mechanics, and as professionals we apply it with varying levels of unease as to what it actually means, but Wheeler had a singular attitude. He insistently asked: "How come the quantum?" Why is the world quantum mechanical? What would happen if we made small changes to quantum mechanics? The preface asks the same sort of questions as Wheeler: "Could it be that quantum mechanics is the simplest mechanics consistent with the existence of conscious beings?" Or does it "optimise the information processing power of the universe"? These are profound questions, as yet unanswered but extensively and profoundly discussed, and some sense of the debate can be found in this book.

Wheeler was the inspiration behind the most extreme connection of all: that quantum mechanics, a theory of subatomic dimensions, can be applied to cosmology, the largest system of all. In response to Einstein's question "Did God have any choice in the nature of his creation?", Wheeler has suggested that there are no truly fixed fundamental laws of physics at all. He was a remarkable man and this is a remarkable volume.

Frank Close is at the Rudolf Peierls Centre for

Theoretical Physics, University of Oxford,

1 Keble Road, Oxford OX1 3NP, UK. 